\title{
Salmon lice nauplii and copepodids display different vertical migration patterns in response to light
}

\author{
A. Szetey ${ }^{1}$, D. W. Wright ${ }^{2,3}$, F. Oppedal ${ }^{2}$, T. Dempster ${ }^{1, *}$ \\ ${ }^{1}$ Sustainable Aquaculture Laboratory — Tropical and Temperate (SALTT), School of BioSciences, University of Melbourne, \\ Victoria 3010, Australia \\ ${ }^{2}$ Institute of Marine Research, Matre Aquaculture Research Station, Matredal 5984, Norway \\ ${ }^{3}$ Department of Primary Industries, Narrandera Fisheries Centre, PO Box 182, Narrandera, New South Wales 2700, Australia
}

\begin{abstract}
Light is a fundamental environmental cue which influences the migration of many marine organisms. For the salmon louse Lepeophtheirus salmonis, light is believed to drive the diel vertical migration behaviour of their planktonic larvae. Salmon lice are of critical importance to the salmonid industry due to the damage they cause to wild and farmed hosts. Salmon lice larvae have an eyespot and are positively phototactic, yet how light intensity alters their vertical distribution remains unclear. Here, we tested how light intensity $\left(0,0.5,10\right.$ and $\left.80 \mu \mathrm{mol} \mathrm{m}^{-2} \mathrm{~s}^{-1}\right)$, dispersal duration (1,4 and $12 \mathrm{~h}$ ) and release point (surface or bottom) influenced the vertical migration of salmon lice nauplii and copepodids under controlled conditions in experimental columns. Overall, higher light intensity increased the proportion of nauplii that aggregated at the surface. Copepodid behaviour differed from that of nauplii, as they swam upwards in both light and fully dark conditions, and surface aggregations increased with dispersal duration. Results from the experiments did not support the existing view that light strongly influences the vertical position of copepodids in the water column. Combined with previous work, our results reveal that salmon lice larval stages display different vertical responses to light, temperature and salinity, which may be explained by the different strategies of nauplii (maximise survival and dispersal) and copepodids (maximise host-finding success). Our results have implications for salmon lice dispersal models, where responses of copepodids and nauplii to light are currently parametrised by the same equations. Implementing stage-specific behaviours towards light may improve the outputs of dispersal models.
\end{abstract}

KEY WORDS: Atlantic salmon · Aquaculture - Dispersal $\cdot$ Lepeophtheirus salmonis $\cdot$ Parasite · Salmo salar

\section{INTRODUCTION}

The salmon louse Lepeophtheirus salmonis is a marine ectoparasite found throughout the Northern Hemisphere that principally infests salmonids (Johnson \& Albright 1991, Stien et al. 2005). They hatch as free-swimming, planktonic larvae and must find and infest a salmonid host to mature and reproduce. During their planktonic life stages, salmon lice are positively phototactic (Bron et al. 1993, Heuch et al. 1995), swimming upwards during daylight, and thus

*Corresponding author: dempster@unimelb.edu.au are thought to follow a reverse diel vertical migration (DVM) pattern (Heuch et al. 1995). As larvae, salmon lice nauplii and copepodids are negatively buoyant, and their downward migration results from passive sinking (Bricknell et al. 2006). Heuch et al. (1995) proposed that sea lice copepodids evolved the reverse migration pattern to infect wild salmonids by aggregating in surface waters during the day and sinking deeper at night. This migration pattern means that sea trout Salmo trutta or outmigrating Atlantic salmon $S$. salar would swim through sinking

(1) The authors 2021. Open Access under Creative Commons by Attribution Licence. Use, distribution and reproduction are unrestricted. Authors and original publication must be credited. 
and rising sea lice copepodids at some point each day, maximising encounter rates between copepodids and salmon for better infection success.

Open net-pen salmonid aquaculture has expanded rapidly in coastal waters, creating the perfect conditions for salmon lice to proliferate (Costello 2009). Salmon lice feed on the blood, skin and mucus of host fish (Pike \& Wadsworth 1999, Costello 2006). High infestation rates cause physical stress to hosts, including osmoregulatory problems, reduced growth rates and severe skin lesions/wounds which leave the host fish vulnerable to infections (Costello 2006, Hamre et al. 2009). The synergistic effect and increasing severity of these symptoms can lead to mortality (Stien et al. 2005). High infestation rates are not exclusive to farmed salmon, as parasite spillback from farmed to wild salmon can lead to considerable parasite loads with negative effects on wild populations (Costello 2009, Krkošek et al. 2013).

Norway's aquaculture industry has invested heavily in the control of salmon louse infestations since the industry's inception (Roth 2000, Hamilton-West et al. 2012). Infestation control is expensive (Abolofia et al. 2017) and negatively impacts the welfare of salmon within farms (Overton et al. 2019). The ability of lice to evolve resistance to treatments means no single remedy is permanent (Mennerat et al. 2010, Coates et al. 2021). Chemotherapeutants were the dominant delousing treatment method until 2015, but have been quickly replaced by mechanical and thermal methods due to widespread resistance (Overton et al. 2018, 2019).

Recent efforts have sought to limit infestations with measures that reduce host-parasite encounter rates rather than waiting for infestations and then applying treatments (see Barrett et al. 2020 for review). Infective-stage planktonic lice respond to light, salinity, temperature and pressure; their combined responses to these environmental variables mean that they are mainly distributed in surface waters (Heuch 1995, Heuch et al. 1995, Samsing et al. 2016b, Crosbie et al. 2019, 2020, Coates et al. 2020). Barrier technologies such as skirts and snorkel cages take advantage of this behaviour by blocking water in the upper layers from carrying salmon lice into cages (Samsing et al. 2016a, Oppedal et al. 2017, Wright et al. 2017, Geitung et al. 2019). This prevents infestation with minimal adverse effects on fish welfare (Stien et al. 2016, Oppedal et al. 2019). To improve the effectiveness of such barrier technologies, defining when, where and how barriers can be best matched to the depths of infective stage lice larvae will reduce infection. Therefore, research is needed to understand how environmental conditions fundamentally influence salmon lice vertical migration.

Salinity, light, temperature and pressure play an important part in the development, distribution and success of the free-swimming larval stages of salmon lice (Samsing et al. 2016b, Brooker et al. 2018, Crosbie et al. 2019, 2020, Coates et al. 2020). Differences are evident in the way the non-infectious nauplii and infectious copepodid stages respond. Larvae avoid low-salinity waters and aggregate at or just beneath a halocline (Heuch 1995, Bricknell et al. 2006, Crosbie et al. 2019), with copepodids less sensitive to brackish layers than nauplii. While nauplii actively choose depths with cooler temperatures, copepodids do not respond to temperature differences (Crosbie et al. 2020). Temperature also heavily influences development and growth duration of salmon lice (Samsing et al. 2016b). Pressure also acts as a strong environmental cue, with increased upwards swimming speeds by copepodids registered in response to pressure change (Coates et al. 2020).

Light is thought to play an influential role in vertical positioning, as copepodids sense light via their eyespot and exhibit positive phototaxis (Johannessen 1977), swimming upwards towards light (Bron et al. 1993). Copepodids are susceptible to ultraviolet radiation (Aarseth \& Schram 2002) and may migrate downwards to avoid damaging levels of exposure (Aarseth \& Schram 1999). Field studies have demonstrated differences in the day and night distributions of copepodids sampled from closed enclosures (Heuch et al. 1995) and within a laboratory setup testing salinities (Heuch 1995). Small-scale experimental setups have revealed that copepodids respond strongly, with active swimming bursts towards light of different intensities and wavelengths and on-off light signals (Novales Flamarique et al. 2000, Fields et al. 2018, Nordtug et al. 2020), but how these short-term responses influence longer-term vertical distribution in the water column remains unknown. Further, nauplii have not shown evidence of DVM (Heuch et al. 1995). While there are observations of nauplii swimming towards the surface, unless newly hatched, moulting or dying (Johannessen 1977), little is known regarding their responses to light.

Model-based predictions of salmon lice dispersal are a key element to prevent infestations via spatial management (Sandvik et al. 2016) and plan future salmon production levels (Myksvoll et al. 2018). Identifying environmental parameters which alter the vertical distribution of salmon lice is essential to model their dispersal in coastal waters, as vertical migration behaviour influences horizontal distribu- 
tion (Johnsen et al. 2014, 2016, Samsing et al. 2016a, Sandvik et al. 2020).

Light intensities in Northern Hemisphere latitudes where salmon lice occur $\left(\sim 50-70^{\circ} \mathrm{N}\right)$ vary in the environment on short to long temporal scales, from dawn/dusk levels, full daylight and full night within a $24 \mathrm{~h}$ period, to environmental conditions such as cloudy weather and season. Determining how nauplii and copepodids respond to different light intensities will provide a deeper understanding of their vertical distribution under different conditions. Here, we tested the vertical distribution of salmon lice under different lighting regimes across experiments using small $(0.8 \mathrm{~m})$ vertical columns. Our experiment exposed nauplii and copepodids to a range of light intensities, from full darkness to daylight, and assessed their distributions after different durations to disperse.

\section{MATERIALS AND METHODS}

\subsection{Experimental and lice collection locations}

Wild adult Lepeophtheirus salmonis were collected from a commercial salmon farm in western Norway $\left(60^{\circ} \mathrm{N}\right)$ in early August. Lice were immediately transported to the Matre Research Station of the Institute of Marine Research, Norway, where a source population was developed for experiments carried out in September-October 2018. For lice production, 4 holding tanks containing approximately 20 salmon infested with adult lice were kept at $12^{\circ} \mathrm{C}$ under a $12 \mathrm{~h}$ light:12 $\mathrm{h}$ dark regime for the duration of the experiment.

\subsection{Egg string collection and incubation}

Salmon lice egg strings were collected from the infested fish twice a week. Initial egg strings produced were not used due to the high variability in length and egg size (Heuch et al. 2000). Subsequent egg strings were collected from fish lightly sedated with $100 \mathrm{mg} \mathrm{l}^{-1}$ of tricaine methanesulfonate (Finquel $\left.{ }^{\circledR}\right)$. Female lice were extracted from infested fish, and their egg strings were removed using forceps. Egg strings were transferred to incubators supplied with continuous flowing seawater under the same conditions $\left(12^{\circ} \mathrm{C}\right)$ as the holding tanks. During incubation for nauplii and copepodids, egg strings were incubated individually to control life stage. Egg strings which failed to hatch after $9 \mathrm{~d}$ of incubation were excluded.

\subsection{Experimental setup}

The column design contained a glass tube (diameter: $5 \mathrm{~cm}$; height: $85 \mathrm{~cm}$ ) surrounded by a rectangular tank separated into 2 chambers $(20 \times 20 \times 42 \mathrm{~cm})$, each with an input and output for water to continuously flow around the glass tube (Fig. 1). This ensured water was kept at a constant temperature without creating turbulence within the inner tube. Thick black panels ( $5 \mathrm{~mm}$ thick) were used to cover the sides of the column, allowing light to enter only from above. The front panel was attached with a hinge which could be opened for counting at the conclusion of the experiment.

A light was suspended $20 \mathrm{~cm}$ above the column. LIFX-LED A19 1100 lumen light bulbs $(11 \mathrm{~W}=75 \mathrm{~W}$ filament lightbulb) were fitted into aluminium floor lamps (IKEA LERSTA). These bulbs were specifically selected as they are controlled through an application connected to Wi-Fi which enabled accurate selection of light intensities, and they have a colour spectrum representative of daylight conditions. Across all light intensities, the Kelvin colour temperature (K) was set to $5500 \mathrm{~K}$, which is equivalent to daylight. Irradiance was measured every $20 \mathrm{~cm}$ (Fig. 2).

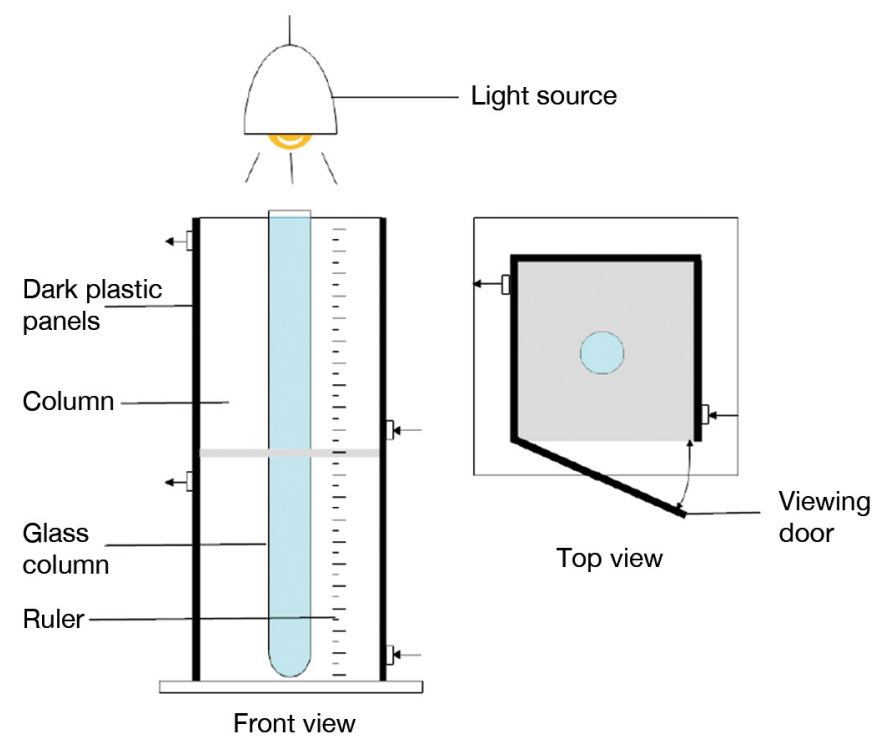

Fig. 1. The $80 \mathrm{~cm}$ column used in Expt 1 to test the vertical distribution of Lepeophtheirus salmonis nauplii and copepodids under different conditions. A glass column (diameter: $5 \mathrm{~cm}$; height: $85 \mathrm{~cm}$ ) was positioned in the centre of a chamber split into 2 sections $(20 \times 20 \times 42 \mathrm{~cm})$, each with an input and output for water to continuously flow. This ensured water within the glass column remained at a constant temperature without creating internal turbulence. Arrows indicate flow direction in the outer chamber. Thick black lines: plastic panels $(5 \mathrm{~mm})$ used to surround the column; front panel was attached with a hinge to allow easy view when tests ended. Light source was suspended $20 \mathrm{~cm}$ above the column 


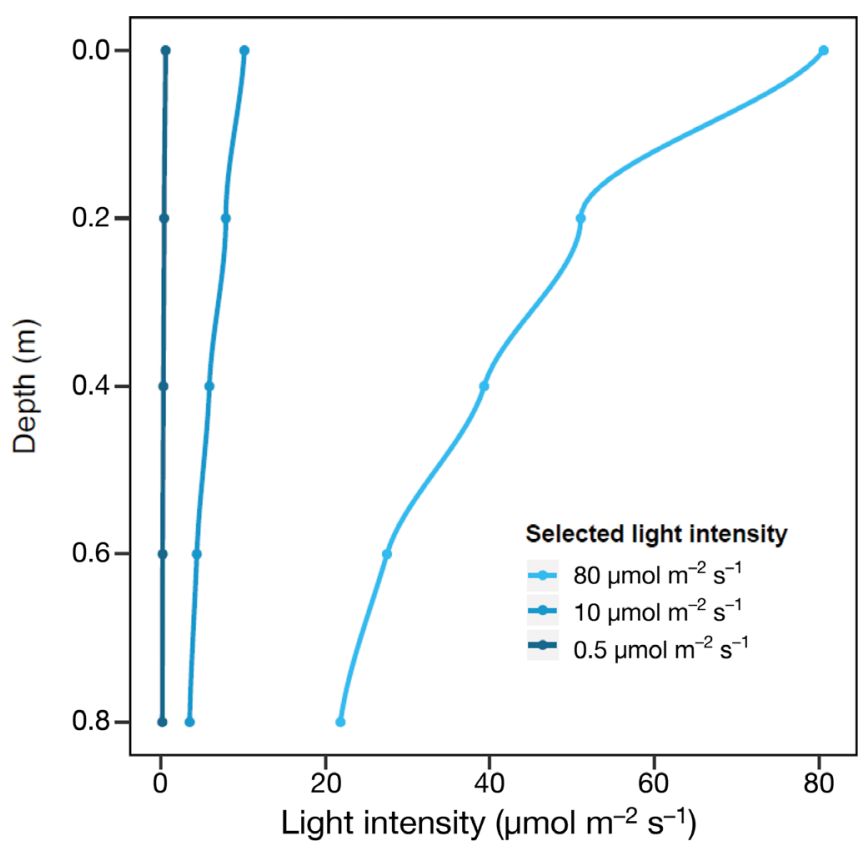

Fig. 2. Light attenuation curve for experimental light intensities. Measurements were taken at every $20 \mathrm{~cm}$ in the column

\subsection{Expt 1: Release-point comparisons for nauplii and copepodids}

In previous experiments that tested the preferences of lice larvae in columns (Heuch 1995, Crosbie et al. 2019), larvae were released into the bottom of the column. As release point could affect vertical distribution, we tested if release point (surface or bottom) and duration influenced vertical distribution of nauplii and copepodids (Table 1). Into each column replicate, approximately 100 salmon lice were released via a peristaltic pump into the bottom or poured into the top of the column. When releasing salmon lice from the top, the column was filled leaving $100 \mathrm{ml}$ where the remaining seawater was gently poured into the column containing the required salmon lice. An additional $2 \mathrm{ml}$ of fresh water was pipetted gently at the top of the column to prevent salmon lice leaping above the meniscus. Due to the phototactic behaviour of salmon lice, release-point comparisons were conducted only in dark treatments $\left(0 \mu \mathrm{mol} \mathrm{m} \mathrm{m}^{-2}\right.$ $\left.\mathrm{s}^{-1}\right)$ for nauplii after $1 \mathrm{~h}(2$ release points $\times 4$ replicates $=8$ columns total; Table 1 ) and copepodids after 1,4 and $12 \mathrm{~h}$ ( 2 release points $\times 3$ durations $\times 4$ replicates $=24$ columns total; Table 1 ).

\subsection{Expts 2 and 3: Vertical distribution of nauplii and copepods in response to light intensity}

As release point did not alter nauplii distribution and had relatively small effects on copepodid distribution in Expt 1, we chose to release larvae from the bottom. For Expts 2 and 3, we exposed lice in columns to one of 4 light intensities $\left(0,0.5,10\right.$ and $80 \mu \mathrm{mol} \mathrm{m}{ }^{-2}$ $\mathrm{s}^{-1}$; Table 1). Light intensities were calculated from the light bulb's full capacity $\left(100 \%=80 \mu \mathrm{mol} \mathrm{m} \mathrm{m}^{-2} \mathrm{~s}^{-1}\right)$ to its lowest capacity $\left(1 \%=0.5 \mu \mathrm{mol} \mathrm{m} \mathrm{m}^{-2} \mathrm{~s}^{-1}\right)$ when measured at the surface of the water using a LI-193SA spherical quantum sensor (LI-COR) with a sensitivity down to $0.01 \mu \mathrm{mol} \mathrm{s} \mathrm{m}^{-1} \mathrm{~m}^{-2}$ and a LI1400 logger unit. These light intensities represent daylight and dawn/ dusk light respectively. We added $10 \mu \mathrm{mol} \mathrm{m} \mathrm{m}^{-2} \mathrm{~s}^{-1}$, which was used in Heuch (1995), to enable comparison with the results of previous research, as well as an absence of light $\left(0 \%=0 \mu \mathrm{mol} \mathrm{m} \mathrm{m}^{-2} \mathrm{~s}^{-1}\right)$ to represent night. A light attenuation curve was created to map how light dispersed through the column (Fig. 2).

Table 1. Experimental designs and environmental parameters under which the vertical distribution of Lepeophtheirus salmonis nauplii and copepodids were tested in response to different release points, depths and light intensities

\begin{tabular}{|c|c|c|c|}
\hline Parameters & Expt 1 & Expt 2 & Expt 3 \\
\hline Testing period & September 2018 & September 2018 & September 2018 \\
\hline No. of lice per replicate column & $\sim 100$ & $\sim 100$ & $\sim 100$ \\
\hline Depth (m) & 0.8 & 0.8 & 0.8 \\
\hline Salinity $(\%)$ & 34.9 & 34.9 & 34.9 \\
\hline Mean temperature $\left({ }^{\circ} \mathrm{C}\right)$ & 9.8 & 9.6 & 9.7 \\
\hline Life stage & Nauplii and copepodids & Nauplii & Copepodids \\
\hline \multicolumn{4}{|l|}{ Design } \\
\hline Surface light intensity $\left(\mu \mathrm{mol} \mathrm{m}{ }^{-2} \mathrm{~s}^{-1}\right)$ & 0 & $0,0.5,10,80$ & $0,0.5,10,80$ \\
\hline Release point & Bottom and surface & Bottom & Bottom \\
\hline Duration (h) & 1 (nauplii); 1, 4, 12 (copepodids) & 1 & $1,4,12$ \\
\hline No. of replicates & 4 & 4 & 4 \\
\hline Total no. of columns & 8 (nauplii) + 24 (copepodid) & 16 & 48 \\
\hline
\end{tabular}


For Expt 2, nauplii were exposed to a specific light intensity for $1 \mathrm{~h}$ due to the shorter lifespan of nauplii ( 4 light intensities $\times 4$ replicates $=16$ columns total; Table 1). In Expt 3, copepodids were tested at each light intensity for 1,4 and $12 \mathrm{~h}$, to understand in greater detail how copepodids behave over a longer period (4 light intensities $\times 3$ durations $\times 4$ replicates $=$ 48 columns total; Table 1$)$.

At the conclusion of each duration, the front black panel was removed, and, using a LED LENSER M5 (140 lumen) torch, lice were counted over a 2 min period with their corresponding distributions recorded on a long piece of paper held adjacent to the column (Crosbie et al. 2019). Lice were considered deceased and excluded from the count if they remained immobile at the bottom of the column.

\subsection{Statistical analysis}

Count data of salmon lice larvae within depth bands were converted into proportions of the total number of lice in each column. Proportions of lice were aggregated to every $10 \mathrm{~cm}$ of the vertical column. Light intensity, duration and release point were the factors compared, depending on the experiment (Table 1). Salmon lice distributions were fitted with generalised additive models (GAMs) using the 'mcgv' package (Wood 2011) in R (R Core Team 2013).

A hierarchical GAM model (Pedersen et al. 2019) was fitted for each experiment to compare life stage, light intensity, release point and duration (Tables S1S4 in the Supplement at www.int-res.com/articles/ suppl/q013p121_supp.pdf). Proportional data were square-root transformed to reduce heteroscedasticity. A model was created to analyse each experiment. Thin plate regression splines (TPRS) were used for the smooth terms. Basis functions were set to $k=5$ for depth smoothing and $k=3$ for factor smoothing. A maximum likelihood test ('compareML'; Table 2) was run through the 'itsadug' package (van Rij et al. 2015). Factors were scored using a $\chi^{2}$ test on the difference between the full model and a null model which had the selected factor removed (Table 2).

\section{RESULTS}

\subsection{Expt 1: Release-point comparisons for nauplii and copepodids}

After $1 \mathrm{~h}$ at $0 \mu \mathrm{mol} \mathrm{m} \mathrm{m}^{-2} \mathrm{~s}^{-1}$, release point did not influence nauplii distributions (surface: $F<0.001, \mathrm{p}=$
0.37, $\mathrm{n}=4$; bottom: $F<0.001, \mathrm{p}=0.37, \mathrm{n}=4$; Fig. 3, Table S1). Nauplii proportions were most aggregated at either the surface or bottom $10 \mathrm{~cm}$ of the column, with few nauplii detected within the middle section of the column regardless of release point $(10-70 \mathrm{~cm}$; Fig. 3).

For copepodids, release point $\left(\chi^{2}=20\right.$, df $=4, \mathrm{p}<$ $0.001)$ and duration $\left(\chi^{2}=82, \mathrm{df}=5, \mathrm{p}<0.001\right)$ both affected vertical dispersal (Fig. 4). Duration had a greater effect than release point, with copepodids

Table 2. Generalised additive model comparison of maximum likelihood for the vertical distribution of Lepeophtheirus salmonis nauplii and copepodids. A null model (selected factor omitted) was compared against the full-factored model for each test to determine level of significance of the omitted factor; $p$-values $<0.05$ are in bold

\begin{tabular}{|lcccc|}
\hline Test & $\begin{array}{c}\text { Model omitted } \\
\text { factor }\end{array}$ & $\begin{array}{c}\text { Differ- } \\
\text { ence }\left(\chi^{2}\right)\end{array}$ & df & p \\
\hline 1.1: Nauplii & Release point & 0.006 & 3 & 1 \\
1.1: Copepodids & Release point & 20 & 4 & $<\mathbf{0 . 0 0 1}$ \\
& Duration & 82 & 5 & $<\mathbf{0 . 0 0 1}$ \\
1.2: Nauplii & Light intensity & 18 & 5 & $<\mathbf{0 . 0 0 1}$ \\
1.3: Copepodids & Duration & 62 & 9 & $<\mathbf{0 . 0 0 1}$ \\
& Light intensity & 27 & 10 & $<\mathbf{0 . 0 0 1}$ \\
2: Copepodids & Release point & 34 & 9 & $<\mathbf{0 . 0 0 1}$ \\
& Light intensity & 11 & 9 & $\mathbf{0 . 0 0 9}$ \\
& Duration & 2.7 & 9 & 0.81 \\
\hline
\end{tabular}

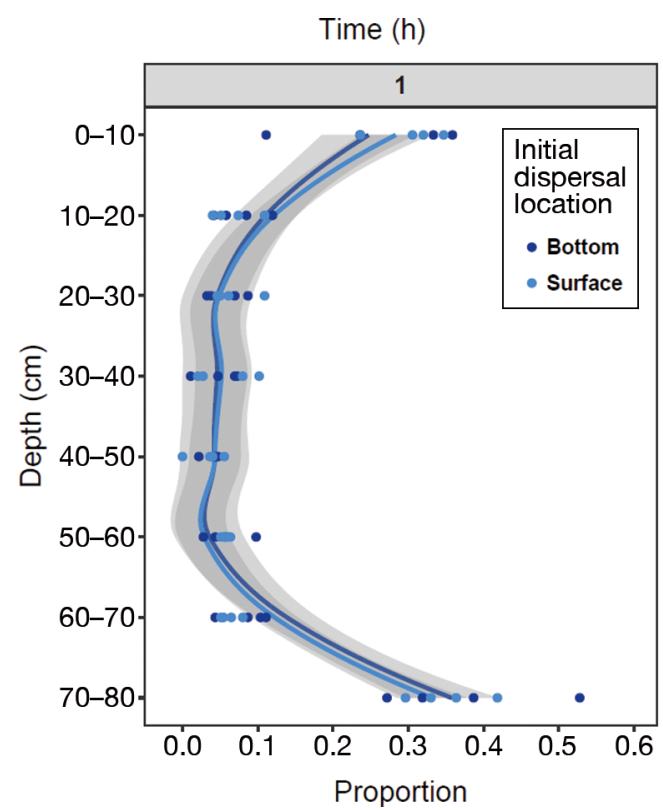

Fig. 3. Proportion of salmon lice Lepeophtheirus salmonis nauplii found in $10 \mathrm{~cm}$ increments within the column (0$80 \mathrm{~cm}$ ) exposed to $0 \mu \mathrm{mol} \mathrm{m}{ }^{-2} \mathrm{~s}^{-1}$ after $1 \mathrm{~h}$. Lice were released from either the surface or the bottom of the column at the beginning of the experiment. Points: individual data points; lines: smoothed loess average; shading: SE 


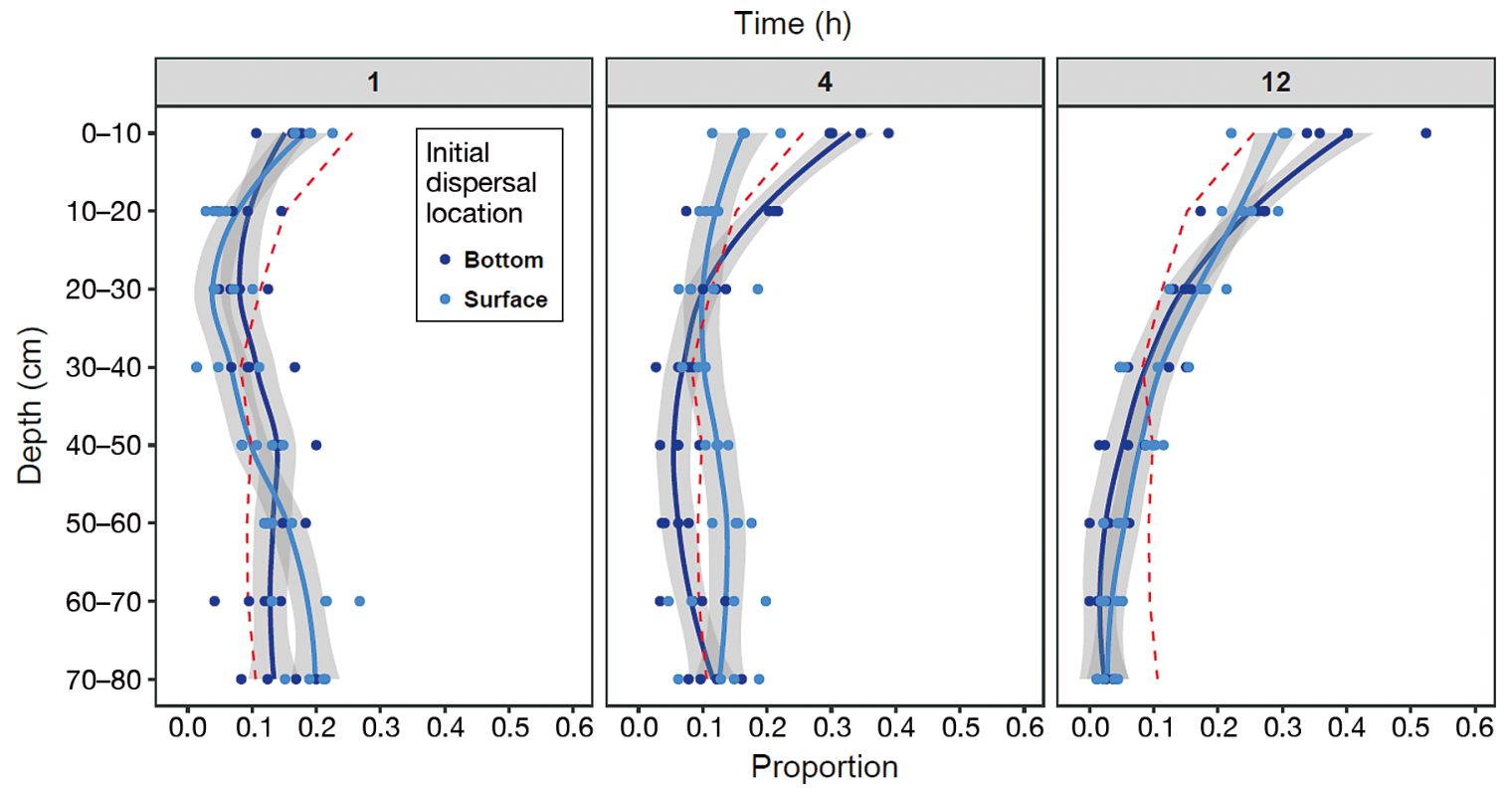

Fig. 4. Proportion of salmon lice Lepeophtheirus salmonis copepodids found in $10 \mathrm{~cm}$ increments within the column $(0-80 \mathrm{~cm})$ exposed to $0 \mu \mathrm{mol} \mathrm{m} \mathrm{m}^{-2} \mathrm{~s}^{-1}$ after 1,4 and $12 \mathrm{~h}$. Lice were released from either the surface or the bottom of the column at the beginning of the experiment. Points: individual data points; lines: smoothed loess average; shading: SE. Red dashed line: overall average used to compare distributions in generalised additive model analysis

increasing their presence in the surface as duration increased. Release point had a greater influence on dispersal after $4 \mathrm{~h}$. At 1 and $12 \mathrm{~h}$, differences in copepodid distributions were only observed in the 60-70 and $0-10 \mathrm{~cm}$ column depth bands respectively.

\subsection{Expt 2: Vertical distributions of nauplii under various light intensities}

Nauplii aggregated within the surface and bottom $10 \mathrm{~cm}$ of the column for all light intensities (Fig. 5). The 0 and $0.5 \mu \mathrm{mol} \mathrm{m}^{-2} \mathrm{~s}^{-1}$ light treatments showed similar distributions $\left(0\right.$ and $0.5 \mu \mathrm{mol} \mathrm{m} \mathrm{m}^{-2} \mathrm{~s}^{-1}: \mathrm{p}=0.2$; Table S3). When light levels were $\geq 10 \mu \mathrm{mol} \mathrm{m}{ }^{-2} \mathrm{~s}^{-1}$, the proportion of nauplii in the surface $10 \mathrm{~cm}$ of the column increased $\left(10\right.$ and $80 \mu \mathrm{mol} \mathrm{m}{ }^{-2} \mathrm{~s}^{-1}: \mathrm{p}<0.001$; Table 3).

\subsection{Expt 3: Vertical distributions of copepodids under various light intensities}

Light intensity $\left(\chi_{[10, \mathrm{n}=16]}^{2}=27, \mathrm{p}<0.001\right)$ and duration $\left(\chi_{[9, \mathrm{n}=12]}^{2}=62, \mathrm{p}<0.001\right)$ both influenced the vertical migration of copepodids. There was no predictable relationship between copepodid distribution and increasing light intensity. Copepodids exposed to 0.5 and $80 \mu \mathrm{mol} \mathrm{m} \mathrm{m}^{-2} \mathrm{~s}^{-1}$ were more similarly dis- tributed than at $10 \mu \mathrm{mol} \mathrm{m} \mathrm{m}^{-2} \mathrm{~s}^{-1}$, where fewer lice were observed at the surface $(F=2.8, \mathrm{p}<0.001, \mathrm{n}=$ 12 ; Table S4). In contrast to the nauplii distributions, copepodids only aggregated at the surface (Fig. 6). Generally, surface aggregation increased with duration; $1 \mathrm{~h}$ treatments had the lowest surface aggregation overall irrespective of light intensity $(F=3.5, \mathrm{p}<$ $0.001, \mathrm{n}=16$; Table S4). The $1 \mathrm{~h}$ duration at $0 \mu \mathrm{mol}$ $\mathrm{m}^{-2} \mathrm{~s}^{-1}$ was the only treatment group which uniformly dispersed in the column. At $4 \mathrm{~h}$, surface aggregation increased at $0.5 \mu \mathrm{mol} \mathrm{m} \mathrm{m}^{-2} \mathrm{~s}^{-1}$, which had a stronger surface aggregation than all other $4 \mathrm{~h}$ treatments $(F=$ $2.8, \mathrm{p}<0.001, \mathrm{n}=4$; Table S4). The $12 \mathrm{~h}$ treatments showed the strongest surface aggregation, with all but one of the $12 \mathrm{~h}$ treatments $\left(10 \mu \mathrm{mol} \mathrm{m}^{-2} \mathrm{~s}^{-1}\right)$ having the highest average proportion of copepodids at the surface within each light intensity level.

\section{DISCUSSION}

Through a series of experiments under controlled conditions, we demonstrated important aspects of salmon louse larval behaviour that are pertinent to efforts to prevent infestations in salmon farms. First, under the same experimental conditions, lice nauplii and copepodids displayed different vertical migration patterns in response to light. Second, while salmon copepodids were phototactic and swam upwards 


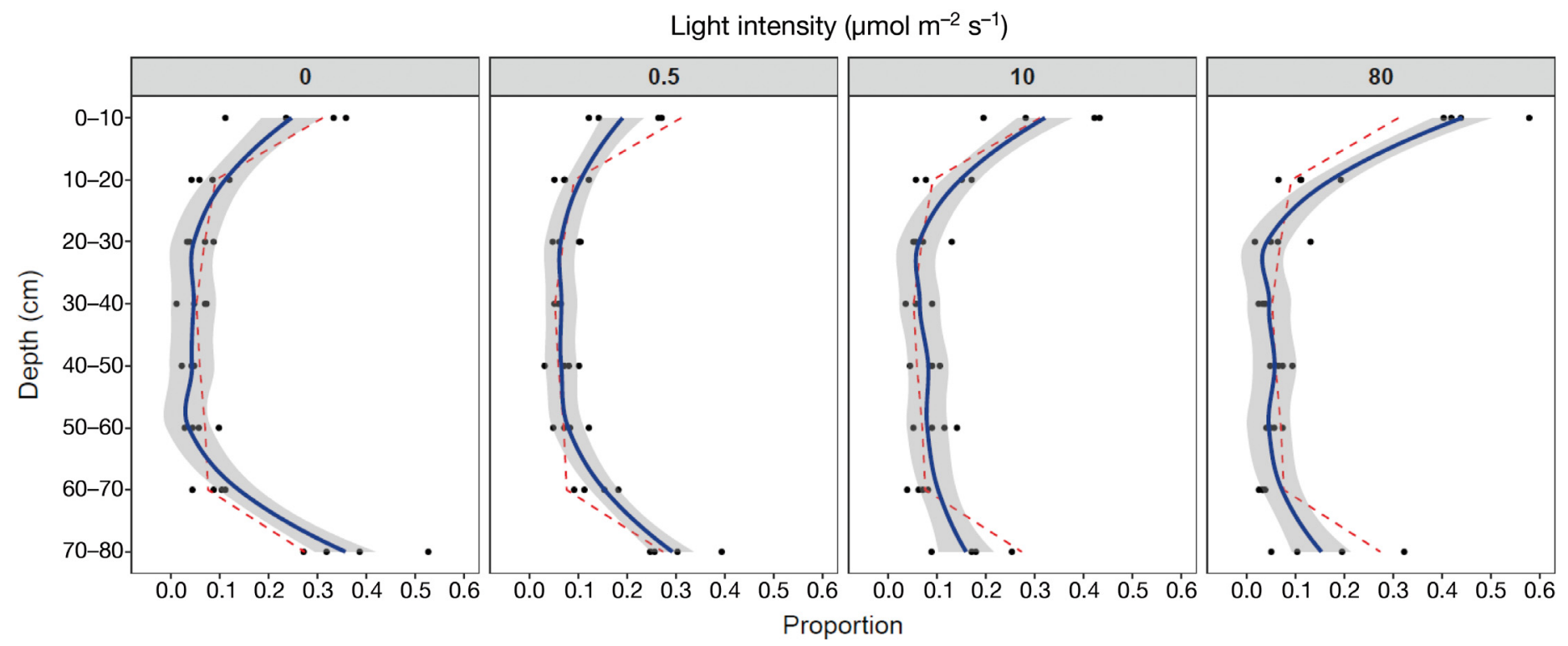

Fig. 5. Proportion of salmon lice Lepeophtheirus salmonis nauplii found in $10 \mathrm{~cm}$ increments of the column (0-80 cm) exposed to $0,0.5,10$ or 80 $\mu \mathrm{mol} \mathrm{m} \mathrm{m}^{-2} \mathrm{~s}^{-1}$ after $1 \mathrm{~h}$. Points: individual data points; lines: smoothed loess average; shading: SE. Red dashed line: overall average used to compare distributions in generalised additive model analysis

more rapidly when light intensity was high, over time the distribution of copepodids was equivalent in full darkness and full sunlight conditions, unexpectedly revealing, for the first, time that copepodids can swim upwards, rather than sink, under night conditions. If these results hold true in larger-scale experiments, they overturn the current paradigm of understanding proposed by Heuch (1995) that copepodids undergo DVM whereby they swim upwards during the day and sink at night.

\subsection{Differences in the vertical distribution of nauplii and copepodids in response to light}

Our results provide new knowledge on the responses of salmon lice larvae to environmental variability. This research also extends on previous work conducted by Heuch (1995) on responses to light and recent research on responses to other environmental variables (Crosbie et al. 2019, 2020). The phototactic behaviour of nauplii had a clearer effect on their vertical distribution compared to copepodids. Nauplii responded strongly and ascended more rapidly as light intensity increased; this result is novel as vertical distributions of nauplii have not previously been tested. In contrast, copepodids preferentially swam to the surface irrespective of the presence of light. Our results suggest salmon lice copepodids will predominantly aggregate towards the surface of the ocean during both day and night. These results add to recent work which reveals that responses to environmental variables are life-stage specific. Salmon lice nauplii and copepodids respond differently to salinity (Crosbie et al. 2019) and temperature (Crosbie et al. 2020) variation in the water column. These differences may be explained by the different strategies of the non-parasitic nauplii stage, where maximising growth, survival and dispersal may be most important, compared to the parasitic copepodid stages that must find a salmon host to develop further, and therefore distributions will be at depths that maximise host encounters. Our results reaffirm the need to understand both nauplii and copepodid life stages, as the behaviour of nauplii will inherently affect the distribution and dispersibility of copepodids.

A key difference between nauplii and copepodid distributions was the high proportion of nauplii present at the bottom of columns, which was absent in columns with copepodids. This higher proportion in the bottom may be due to some individuals entering a moulting phase (either into nauplii II or copepodid), with lower fitness/mortality (Johannessen 1977), or individuals choosing to remain at the bottom of the column. During moulting, lice are unable to swim, resulting in sinking due to their negative buoyancy (Johannessen 1977, Bricknell et al. 2006). However, the highest proportion of nauplii in the top $10 \mathrm{~cm}$, found at $80 \mu \mathrm{mol} \mathrm{m} \mathrm{m}^{-2} \mathrm{~s}^{-1}$, also had the lowest proportion of nauplii at the bottom $10 \mathrm{~cm}$ compared to any other light intensity. When examining samples under the microscope, a proportion $(<5 \%)$ of nauplii in every 


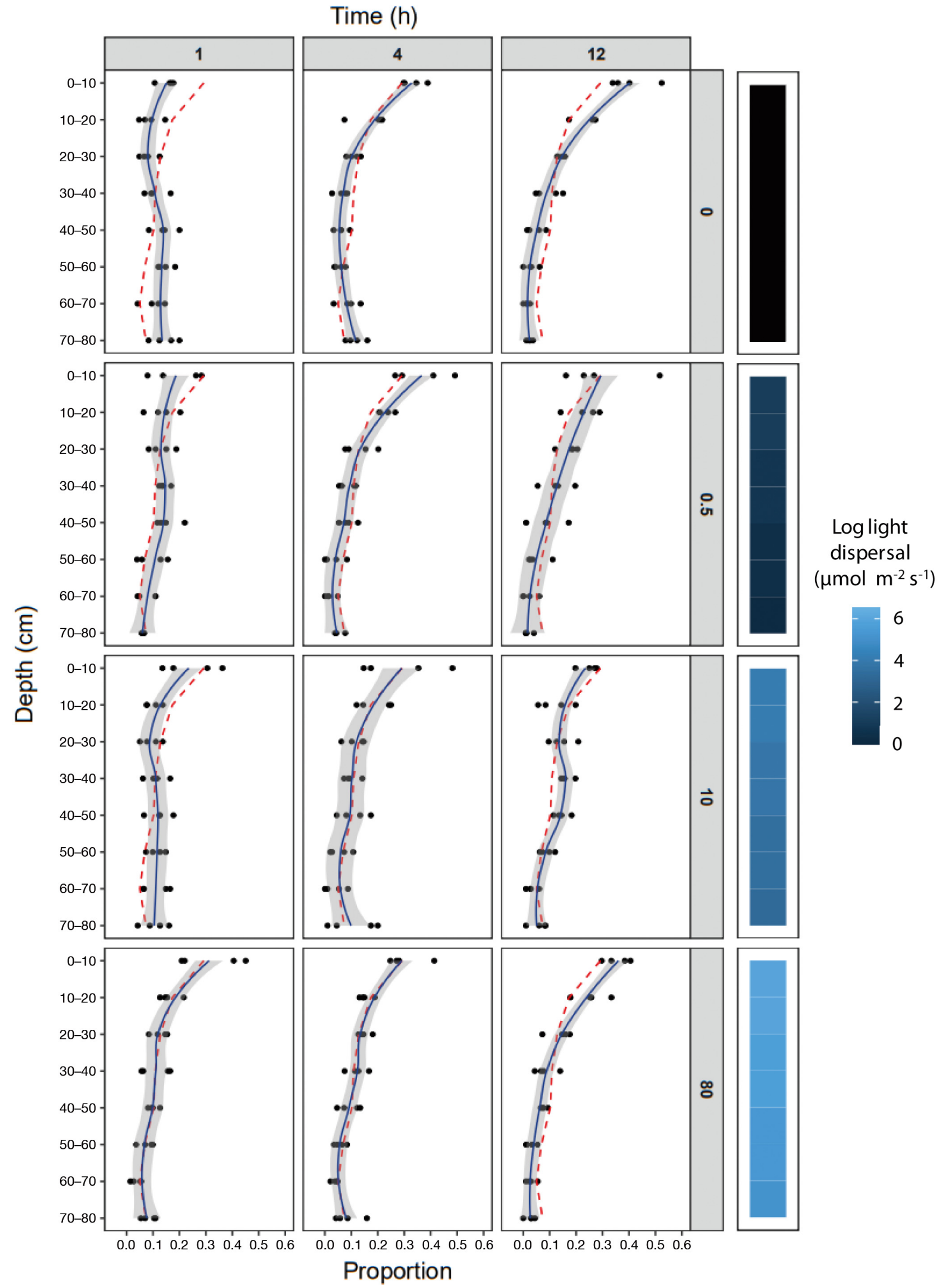

Fig. 6. Proportion of salmon lice Lepeophtheirus salmonis copepodids found in $10 \mathrm{~cm}$ increments in the column (0-80 cm) exposed to $0,0.5,10$ or $80 \mu \mathrm{mol} \mathrm{m}^{-2} \mathrm{~s}^{-1}$ after 1, 4 and $12 \mathrm{~h}$. Points: individual data points; lines: smoothed loess average; shading: SE. Bar graph (right) describes the average log irradiance in $10 \mathrm{~cm}$ increments throughout the column. Red dashed line: overall average used to compare distributions in generalised additive model analysis 
replicate had individuals moulting into either nauplii II or copepodids, and the number of nauplii which had died was negligible (0-5\%). While dead/nonmotile (from moulting) lice were excluded from the data, they only accounted for $\sim 10-40 \%$ of the entire proportion found at the bottom $10 \mathrm{~cm}$ (Fig. 5). This means that many live nauplii were at the bottom of the column choosing not to swim towards the surface, indicating that there are other factors influencing lower depth dispersal.

\subsection{Copepodids ascend regardless of light conditions}

Our results run counter to previous work that suggested copepodids tightly follow a light-induced DVM (Bron et al. 1993, Heuch 1995, Heuch et al. 1995). The similar salinity, temperature and light level conditions under which the experiments by Heuch (1995) and this study were conducted enable close comparison of results. Distributions recorded by Heuch (1995) differed markedly from what we observed. Heuch (1995) observed that salmon lice were strongly aggregated at the surface under a lit environment after $1 \mathrm{~h}$ and that they subsequently sank after $4 \mathrm{~h}$ in a dark environment. Under similar conditions, the salmon lice we tested showed strong surface aggregation, irrespective of light intensity.

We propose several hypotheses to explain the different results including, but not limited to, (1) there were genetic and/or environmental differences in the lice populations used in the 2 experiments, (2) another cue, or combination of cues, influences salmon lice vertical migration, or (3) salmon lice displayed a lightinduced DVM pattern when tested first in the early 1990s, but evolutionary drivers have since altered their distribution after $25 \mathrm{yr}$ of intensive salmon aquaculture.

Prior to intensive aquaculture, the main hosts of salmon lice were wild Atlantic salmon and brown sea trout Salmo trutta, which predominantly swim in surface waters (Eldøy et al. 2017, Hedger et al. 2017). Heuch (1995) suggested diel migration was a mechanism best suited to maximise encounter rates with these largely solitary wild hosts that could be located at various depths in the upper $10 \mathrm{~m}$. Aquaculture has changed the dominant hosts of salmon lice, with farmed salmonids (Atlantic salmon and rainbow trout Oncorhynchus mykiss) now over 250 times more abundant than wild salmonids in Norwegian waters. This translates to $>99 \%$ of available hosts being farmed salmonids (T. Dempster et al. unpubl. data).
Farmed salmon distribute at various depths in the water column but occur in surface waters in daytime during feeding bouts. Further, they frequently aggregate in high densities at the surface at night due to their light preferences (Oppedal et al. 2011, Strøm et al. 2018). An evolutionary sustainable strategy to maximise the probability of finding a farmed salmon host would therefore be to swim upwards regardless of light intensity.

Like any successful parasite, salmon lice rapidly evolve to cope with new circumstances (Mennerat et al. 2010). Chemotherapeutant resistance is one example of how a treatment method was rendered ineffective by rapid evolution. In 2015, chemotherapeutants encompassed $79 \%$ of the treatment regimes in Norway before rapidly declining to $13 \%$ by 2017 (Overton et al. 2019), primarily because of their reduced efficacy due to resistance (Aaen et al. 2015, Helgesen et al. 2015). Although the life-cycle length of a salmon louse is dependent on temperature (Samsing et al. 2016b, Hamre et al. 2019), generations are relatively short (8-10 generations $\mathrm{yr}^{-1}$ ). In the 25 yr since Heuch's (1995) study, 200-250 generations of salmon lice have occurred. Therefore, if vertical migratory behaviour is a heritable trait, as shown for other plankton species (e.g. Daphnia sp.; King \& Miracle 1995), selective pressures induced by the availability of farmed hosts may have altered salmon lice vertical behaviour within this timeframe.

\subsection{Implications for lice prevention technologies and sea lice dispersal models}

Our results demonstrate that infectious-stage copepodids can have similarly surface-skewed distributions under high and low light conditions. This suggests that lice barriers deployed to protect salmon in the upper $10 \mathrm{~m}$ of water could provide similar levels of protection regardless of time of day or season. Effective deployment of these systems can therefore focus on adjusting depths to account for the effects of other environmental variables, such as salinity and pressure, which strongly alter the vertical distribution of copepodids and therefore also the effectiveness of lice barriers (Crosbie et al. 2019, Oppedal et al. 2019, Coates et al. 2020).

Responses to environmental variables are key inputs to combined hydrological-biological models that predict the dispersal of planktonic-stage salmon lice, such as national sea lice dispersal models (e.g. Myksvoll et al. 2018). Previously, responses of nauplii and copepodids to light have been encoded with the 
same equations in these dispersal models (Johnsen et al. 2014, Skarðhamar et al. 2018). Outputs may be improved if stage-specific equations for the responses of nauplii and copepodids to light are enacted. If equations are altered to encode upwards swimming regardless of light intensity, modelled dispersal distances of lice larvae will increase. This effect is because surface waters are typically transported the greatest distances horizontally due to wind-induced forces (Johnsen et al. 2014). Whether these alterations improve existing dispersal models can be determined by ground-truthing via field collections of lice larvae or sentinel cages containing salmonids (Myksvoll et al. 2018, Skarðhamar et al. 2019).

Acknowledgements. We thank Lise Dyrhovden and MartinPeter Matre from the Matre Station, Institute of Marine Research, for assistance during experimental work. Georgia Macaulay and Andrew Coates from the University of Melbourne provided technical assistance. We thank Luke Barrett for assistance in the analysis of the experimental data. All experimental work was performed in accordance with the guidelines of the Norwegian Animal Research Authority (animal ethics permit [FOTS ID] \#12935). Funding was provided by the Norwegian Seafood Research Fund to project \#901283 'Utvikling av lakselus ved ulik temperature og lys (TEMPLUS)'.

\section{LITERATURE CITED}

Aaen SM, Helgesen KO, Bakke MJ, Kaur K, Horsberg TE (2015) Drug resistance in sea lice: a threat to salmonid aquaculture. Trends Parasitol 31:72-81

Aarseth KA, Schram TA (1999) Wavelength-specific behaviour in Lepeophtheirus salmonis and Calanus finmarchicus to ultraviolet and visible light in laboratory experiments (Crustacea: Copepoda). Mar Ecol Prog Ser 186: 211-217

Aarseth KA, Schram TA (2002) Susceptibility to ultraviolet radiation in Calanus finmarchicus and Lepeophtheirus salmonis and the adaptive value of external filtering (Crustacea: Copepoda). J Plankton Res 24:661-679

Abolofia J, Asche F, Wilen JE (2017) The cost of lice: quantifying the impacts of parasitic sea lice on farmed salmon. Mar Resour Econ 32:329-349

* Barrett LT, Oppedal F, Robinson N, Dempster T (2020) Prevention not cure: a review of methods to avoid sea lice infestations in salmon aquaculture. Rev Aquacult 12: 2527-2543

Bricknell IR, Dalesman SJ, O'Shea B, Pert CC, Luntz AJM (2006) Effect of environmental salinity on sea lice Lepeophtheirus salmonis settlement success. Dis Aquat Org 71:201-212

Bron J, Sommerville C, Rae G (1993) Aspects of the behaviour of copepodid larvae of the salmon louse Lepeophtheirus salmonis (Krøyer, 1837). In: Boxshall GA, Defaye D (eds) Pathogens of wild and farmed fish: sea lice. Ellis Harwood, Chichester, p 125-142

Brooker AJ, Skern-Mauritzen R, Bron JE (2018) Production, mortality, and infectivity of planktonic larval sea lice, Lepeophtheirus salmonis (Krøyer, 1837): current knowl- edge and implications for epidemiological modelling. ICES J Mar Sci 75:1214-1234

Coates A, Phillips B, Oppedal F, Bui S, Overton K, Dempster T (2020) Parasites under pressure: salmon lice may adapt to depth-based preventions in aquaculture. Int J Parasitol 50:865-872

* Coates A, Phillips BL, Bui S, Oppedal F, Robinson NA, Dempster T (2021) Evolution of salmon lice in response to management strategies: a review. Rev Aquacult, doi:10.1111/raq.12528

Costello MJ (2006) Ecology of sea lice parasitic on farmed and wild fish. Trends Parasitol 22:475-483

Costello MJ (2009) How sea lice from salmon farms may cause wild salmonid declines in Europe and North America and be a threat to fishes elsewhere. Proc R Soc B 276: 3385-3394

* Crosbie T, Wright D, Oppedal F, Johnsen I, Samsing F, Dempster T (2019) Effects of step salinity gradients on salmon lice larvae behaviour and dispersal. Aquacult Environ Interact 11:181-190

Crosbie T, Wright DW, Oppedal F, Dalvin S, Myksvoll MS, Dempster T (2020) Impact of thermoclines on the vertical distribution of salmon lice larvae. Aquacult Environ Interact 12:1-10

* Eldøy SH, Davidsen JG, Thorstad EB, Whoriskey FG and others (2017) Marine depth use of sea trout Salmo trutta in fjord areas of central Norway. J Fish Biol 91:1268-1283

* Fields DM, Skiftesvik AB, Browman HI (2018) Behavioural responses of infective-stage copepodids of the salmon louse (Lepeophtheirus salmonis, Copepoda: Caligidae) to host-related sensory cues. J Fish Dis 41:875-884

* Geitung L, Oppedal F, Stien LH, Dempster T, Karlsbakk E, Nola V, Wright DW (2019) Snorkel sea-cage technology decreases salmon louse infestation by $75 \%$ in a full-cycle commercial test. Int J Parasitol 49:843-846

*Hamilton-West C, Arriagada G, Yatabe T, Valdés P, HervéClaude LP, Urcelay S (2012) Epidemiological description of the sea lice (Caligus rogercresseyi) situation in southern Chile in August 2007. Prev Vet Med 104:341-345

*Hamre LA, Glover KA, Nilsen F (2009) Establishment and characterisation of salmon louse (Lepeophtheirus salmonis (Krøyer 1837)) laboratory strains. Parasitol Int 58:451-460

*Hamre LA, Bui S, Oppedal F, Skern-Mauritzen R, Dalvin S (2019) Development of the salmon louse Lepeophtheirus salmonis parasitic stages in temperatures ranging from 3 to $24^{\circ} \mathrm{C}$. Aquacult Environ Interact 11:429-443

* Hedger RD, Rikardsen AH, Strøm JF, Righton DA, Thorstad EB, Næsje TF (2017) Diving behaviour of Atlantic salmon at sea: effects of light regimes and temperature stratification. Mar Ecol Prog Ser 574:127-140

Kelgesen KO, Romstad H, Aaen SM, Horsberg TE (2015) First report of reduced sensitivity towards hydrogen peroxide found in the salmon louse Lepeophtheirus salmonis in Norway. Aquacult Rep 1:37-42

*Heuch PA (1995) Experimental evidence for aggregation of salmon louse copepodids (Lepeophtheirus salmonis) in step salinity gradients. J Mar Biol Assoc UK 75:927-939

* Heuch PA, Parsons A, Boxaspen K (1995) Diel vertical migration: A possible host-finding mechanism in salmon louse (Lepeophtheirus salmonis) copepodids? Can J Fish Aquat Sci 52:681-689

*Heuch P, Nordhagen J, Schram T (2000) Egg production in the salmon louse [Lepeophtheirus salmonis (Krøyer)] in relation to origin and water temperature. Aquacult Res 31:805-814 
Johannessen A (1977) Early stages of Lepeophtheirus salmonis (Copepoda, Caligidae). Sarsia 63:169-176

Johnsen IA, Fiksen Ø, Sandvik AD, Asplin L (2014) Vertical salmon lice behaviour as a response to environmental conditions and its influence on regional dispersion in a fjord system. Aquacult Environ Interact 5:127-141

Johnsen IA, Asplin L, Sandvik AD, Serra-Llinares RM (2016) Salmon lice dispersion in a northern Norwegian fjord system and the impact of vertical movements. Aquacult Environ Interact 8:99-116

Johnson S, Albright L (1991) Development, growth, and survival of Lepeophtheirus salmonis (Copepoda: Caligidae) under laboratory conditions. J Mar Biol Assoc UK 71: 425-436

King CE, Miracle MR (1995) Diel vertical migration by Daphnia longispina in a Spanish lake: genetic sources of distributional variation. Limnol Oceanogr 40:226-231

Krkošek M, Revie CW, Gargan PG, Skilbrei OT, Finstad B, Todd CD (2013) Impact of parasites on salmon recruitment in the Northeast Atlantic Ocean. Proc R Soc B 280: 20122359

Mennerat A, Nilsen F, Ebert D, Skorping A (2010) Intensive farming: evolutionary implications for parasites and pathogens. Evol Biol 37:59-67

Myksvoll MS, Asplin L, Sandvik AD, Johnsen IA, Ådlandsvik B, Albretsen J, Skardhamar J (2018) Modelling salmon lice copepodids along the Norwegian coast — comparing old and new particle tracking models. Rapport fra Havforskningen No. 39-2018. Norwegian Institute of Marine Research, Bergen

Nordtug T, Kvæstad B, Hagemann A (2020) Responses and preferences of salmon louse (Lepeophtheirus salmonis Krøyer 1836) copepodids to underwater artificial light sources. Aquaculture 532:736036

Novales Flamarique I, Browman HI, Belanger M, Boxaspen $\mathrm{K}$ (2000) Ontogenetic changes in visual sensitivity of the parasitic salmon louse Lepeophtheirus salmonis. J Exp Biol 203:1649-1657

Oppedal F, Dempster T, Stien LH (2011) Environmental drivers of Atlantic salmon behaviour in sea-cages: a review. Aquaculture 311:1-18

Oppedal F, Samsing F, Dempster T, Wright DW, Bui S, Stien LH (2017) Sea lice infestation levels decrease with deeper 'snorkel' barriers in Atlantic salmon sea-cages. Pest Manag Sci 73:1935-1943

炎Oppedal F, Bui S, Stien LH, Overton K, Dempster T (2019) Snorkel technology to reduce sea lice infestations: efficacy depends on salinity at the farm site, but snorkels have minimal effects on salmon production and welfare. Aquacult Environ Interact 11:445-457

* Overton K, Samsing F, Oppedal F, Dalvin S, Stien LH, Dempster T (2018) The use and effects of hydrogen peroxide on salmon lice and post-smolt Atlantic salmon. Aquaculture 486:246-252

Overton K, Dempster T, Oppedal F, Kristiansen TS, Gismervik K, Stien LH (2019) Salmon lice treatments and salmon mortality in Norwegian aquaculture: a review. Rev Aquacult 11:1398-1417

Editorial responsibility: Bengt Finstad,

Trondheim, Norway

Reviewed by: 3 anonymous referees
Pedersen EJ, Miller DL, Simpson GL, Ross N (2019) Hierarchical generalized additive models in ecology: an introduction with mgcv. PeerJ 7:e6876

Pike AW, Wadsworth SL (1999) Sealice on salmonids: their biology and control. Adv Parasitol 44:233-337

R Core Team (2013) R: a language and environment for statistical computing. R Foundation for Statistical Computing, Vienna

Roth M (2000) The availability and use of chemotherapeutic sea lice control products. Contrib Zool 69:109-118

Samsing F, Johnsen I, Stien LH, Oppedal F, Albretsen J, Asplin L, Dempster T (2016a) Predicting the effectiveness of depth-based technologies to prevent salmon lice infection using a dispersal model. Prev Vet Med 129: 48-57

* Samsing F, Oppedal F, Dalvin S, Johnsen I, Vågseth T, Dempster T (2016b) Salmon lice (Lepeophtheirus salmonis) development times, body size, and reproductive outputs follow universal models of temperature dependence. Can J Fish Aquat Sci 73:1841-1851

Sandvik AD, Bjørn PA, Ådlandsvik B, Asplin L and others (2016) Toward a model-based prediction system for salmon lice infestation pressure. Aquacult Environ Interact 8:527-542

Sandvik AD, Johnsen IA, Myksvoll MS, Sævik PN, Skogen MD (2020) Prediction of the salmon lice infestation pressure in a Norwegian fjord. ICES J Mar Sci 77:746-756

Skarðhamar J, Albretsen J, Sandvik AD, Lien VS and others (2018) Modelled salmon lice dispersion and infestation patterns in a sub-arctic fjord. ICES J Mar Sci 75: 1733-1747

* Skarðhamar J, Nilsen Fagerli M, Reigstad M, Sandvik AD, Bjørn PA (2019) Sampling planktonic salmon lice in Norwegian fjords. Aquacult Environ Interact 11:701-715

Stien A, Bjørn PA, Heuch PA, Elston DA (2005) Population dynamics of salmon lice Lepeophtheirus salmonis on Atlantic salmon and sea trout. Mar Ecol Prog Ser 290: 263-275

* Stien LH, Dempster T, Bui S, Glaropoulos A, Fosseidengen JE, Wright DW, Oppedal F (2016) 'Snorkel' sea lice barrier technology reduces sea lice loads on harvest-sized Atlantic salmon with minimal welfare impacts. Aquaculture 458:29-37

* Strøm JF, Thorstad EB, Hedger RD, Rikardsen AH (2018) Revealing the full ocean migration of individual Atlantic salmon. Anim Biotelem 6:2

van Rij J, Wieling M, Baayen RH, van Rijn H (2015) itsadug: interpreting time series and autocorrelated data using GAMMs. R package version 1. https://cran.r-project.org/ package $=$ itsadug

Wood SN (2011) Fast stable restricted maximum likelihood and marginal likelihood estimation of semiparametric generalized linear models. J R Stat Soc B 73:3-36

* Wright DW, Stien LH, Dempster T, Vågseth T, Nola V, Fosseidengen JE, Oppedal F (2017) 'Snorkel' lice barrier technology reduced two co-occurring parasites, the salmon louse (Lepeophtheirus salmonis) and the amoebic gill disease causing agent (Neoparamoeba perurans), in commercial salmon sea-cages. Prev Vet Med 140:97-105

Submitted: October 19, 2020

Accepted: February 4, 2021

Proofs received from author(s): May 3, 2021 